\title{
Electron microscope study of PNH red cells and AET-treated normal red cells (PNH-like cells)
}

\author{
S. M. LEWIS, G. LAMBERTENGHI, S. FERRONE, AND G. SIRCHIA
}

From the Department of Haematology, Royal Postgraduate Medical School, London, and the Institute of Medical Pathology, University of Milan, Milan, Italy

SYNOPSIS The morphology of red cells damaged by 2-aminoethylisothiouronium bromide (AET) has been compared to that of PNH cells by transmission and scanning electron microscopy. The main features of the effect of AET as demonstrated by the scanning electron microscope were spherical and deformed cells, with surface craters and relatively large pits. The transmission electron microscope revealed loss of surface structure, an unusual amount of irregularly shaped electrondense material and fine pits in the cell membranes. The paroxysmal nocturnal haemoglobinuria cells showed, by transmission electron microscope, electron-dense material scattered over the cell and fine pitting; by scanning electron microscope, larger craters were seen and swellings protruded from the cell surface. Although the AET changes were not identical with the natural abnormality of paroxysmal nocturnal haemoglobinuria, the twotypes of cells were sufficiently similar to each other to support the proposition that AET cells have many of the characteristics of paroxysmal nocturnal haemoglobinuria.

Normal human red cells treated in vitro with the sulhydryl compound 2-aminoethylisothiouronium bromide (AET) acquire many properties of the erythrocytes of paroxysmal nocturnal haemoglobinuria (PNH) (Sirchia, Ferrone, and Mercuriali, 1965). In particular, they are extremely sensitive to the lytic action of complement, and display a low acetylcholinesterase activity (Sirchia, Ferrone, Milani, and Mercuriali, 1966). Cells treated with AET have been extensively used as a substitute for PNH red cells in yarious experiments to try to elucidate the abnormality of the red-cell membrane in paroxysmal nocturnal haemoglobinuria. Structural abnormalities have been demonstrated in the PNH red cell by transmission electron microscopy (Lewis, Danon, and Marikovsky, 1965). These include numerous small pits on the cell surface and an irregular electron-dense material seen in haemoglobin-free cell membranes (ghosts). Scanning electron microscopy is a relatively new technique by means of which it is possible to view the fine details of surface structure in a three-dimensional view with a resolution of 10 to $20 \mathrm{~nm}$. As there is no interference to the image by electron-dense material in the interior of the cell, this is particularly useful in studying the surface of cells (Clarke and Salsbury, 1967; Hayes

Received for publication 30 December 1970. and Pease, 1968). Furthermore, as it is not necessary to have haemoglobin-free ghosts the cells can be fixed immediately, and thus be less likely to undergo artefactual damage.

The study described in this paper was undertaken in order to determine whether the ultrastructural appearances of PNH cells as seen by transmission electron microscopy are reflected in the scanning electron microscope and to compare the appearances of PNH red cells with those of normal cells after damage by AET (PNH-like cells).

\section{Materials and Methods}

Cells were treated with AET and prepared as previously described (Sirchia et al, 1965) using the red cells of four normal subjects. For the production of PNH-like cells as a rule $8 \%$ AET was used; for some experiments a $2 \%$ solution was used.

For preparing the material for scanning electron microscopy, after the last washing with saline the red cells were fixed with $0.5 \%$ glutaraldehyde in phosphate buffer, $p \mathbf{H} \mathbf{7 \cdot 4}$, for 30 minutes at room temperature.

As controls, samples from the same subjects were treated in a similar way except that they were not exposed to AET solution. Freshly collected blood from four patients with paroxysmal nocturnal 
haemoglobinuria was also fixed in $0.5 \%$ phosphatebuffered glutaraldehyde, $p \mathrm{H} 7 \cdot 4$, for 30 minutes. After fixation all cell suspensions were washed three times in glass-distilled water, resuspended in water, and one drop of the suspension was allowed to dry on a cover glass of $10 \mathrm{~mm}$ diameter. After mounting on aluminium stubs the specimens were coated with gold-palladium in a vacuum chamber to a thickness of $50 \mathrm{~nm}$ and examined by a Cambridge electron microscope at an incidence angle of $45^{\circ}$, using Tri-X Kodak or Polaroid film for recording.

For transmission electron microscopy specimens were prepared as follows: approximately $0.05 \mathrm{ml}$ of samples of AET cells, normal controls, and PNH cells were collected into buffered isotonic saline, pH 7.4, washed twice, and resuspended in $10 \mathrm{ml}$ of $0 \cdot 1 \mathrm{M} \mathrm{NaCl}$ buffered at $p \mathrm{H} 7 \cdot 4$, and then dialysed against $0.025 \mathrm{M} \mathrm{NaCl}$ solution in order to obtain haemoglobin-free ghosts, as described by Danon, Nevo, and Marikovsky (1956). The ghosts were concentrated by centrifuging at $5,000 \mathrm{~g}$ for 10 minutes and then fixed in $1 \%$ osmium tetroxide in

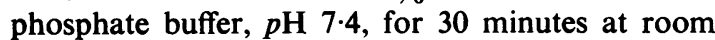
temperature. After fixation the preparations were washed twice with double-distilled water and resuspended to an appropriate concentration in distilled water. One drop of suspension was placed on a Formvar-coated copper grid and dried. Shadow casting by platinum was carried out in a height-toshadow ratio of $1: 4$. The specimens were examined in an AEI electron microscope.

\section{Results}

CELLS OF PAROXYSMAL NOCTURNAL HAEMOGLOBINURIA

On transmission electron microscopy the red cell membranes in all cases showed the abnormalities which have previously been described (Lewis $e t$ al, 1965). These include pitting and electron-dense material scattered throughout the surface of the cell (Fig. 1). The extent of pitting varied; some membranes were markedly pitted whilst others in the same preparation were normal, or showed only a little pitting. The pits were small, of the order of 25 to $50 \mathrm{~nm}$ in diameter.

By scanning electron microscopy the red cells showed moderate variation in size and shape. In some cells there were prominent projections or swellings at the site of the central concavity or at the periphery of the cell (Figs. 2-3). It is not clear what these swellings were due to but it is thought that they are an expression of membrane abnormality. They were not due to underlying nuclear material (as checked in Romanowsky-stained films of the same specimens). We have observed a similar appearance $\stackrel{\overrightarrow{0}}{\overrightarrow{0}}$ in cells from various other blood diseases and even occasionally in normal subjects.

The majority of the cells had a smooth surface; many, however, contained a variable number of craters distributed randomly on the surface (Fig. 4). $\frac{\bar{s}}{\frac{1}{6}}$ The craters were relatively large; they did not $\stackrel{\mathbb{Q}}{\Omega}$ resemble the much smaller pitting observed by transmission electron microscopy.

\section{AET CELLS}

By scanning electron microscopy the red cells showed considerable variation in size and shape. Many cells? lost their central depression and became more iv spherical whilst some appeared grossly deformed in shape (Fig. 5). Some of the cells showed an irregularo roughened surface. Craters and pits were observed $خ$

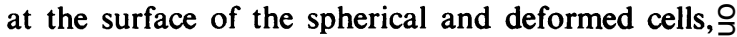
either one or several being present in an affected cell, with the greater number in the more grossly deformed $Z$ cells (Figs. 6-8). These features were seen in cells exposed to $8 \%$ AET. Normal red cells exposed to $2 \%$ AET did not show these defects but when paroxysmal nocturnal haemoglobinuria cells were $\vec{\theta}$ exposed to $2 \%$ AET they showed a marked degree of pitting with numerous craters in each affected cell ${ }^{-}$ (Fig. 9).

After exposure to $8 \%$ AET defects in membranes of cells were less dramatic when examined by the transmission electron microscope. However, the majority showed some abnormalities: the surface of $\mathscr{Q}$ the cells appeared to have lost the normal corrugated $\overrightarrow{\vec{O}}$ appearance (Figs. 10-13); also, there was pitting and 3 an unusual amount of irregularly shaped electrondense material (Figs. 14-15). The appearance was? reminiscent, at least to some extent, of that seen in paroxysmal nocturnal haemoglobinuria (Fig. 1).

\section{Discussion}

It is well established that in paroxysmal nocturnal haemoglobinuria there is a defect in the membrane of the red cell which can be demonstrated in vitro by $\frac{7}{0}$ sensitivity to complement lysis. By transmission electron microscopy a defect in the membrane may ô be shown by the presence of surface pitting and $N$ varying amounts of abnormal electron-dense material. It has not been certain, however, whether ${ }^{\omega}$ the pitting is present in circulating cells or is an artefact induced in vitro during preparation for electron microscopy of red cells weakened because of $\mathscr{\mathscr { Q }}$ a structural defect.

The recent development of the scanning electron $\frac{T}{\circ}$ microscope has provided an instrument which is $\frac{\mathrm{D}}{\mathbb{D}}$ especially suitable for studying the ultrastructure of $\frac{O}{\mathbb{D}}$ the surface of cells. Preparations need the minimum $\cong$ 


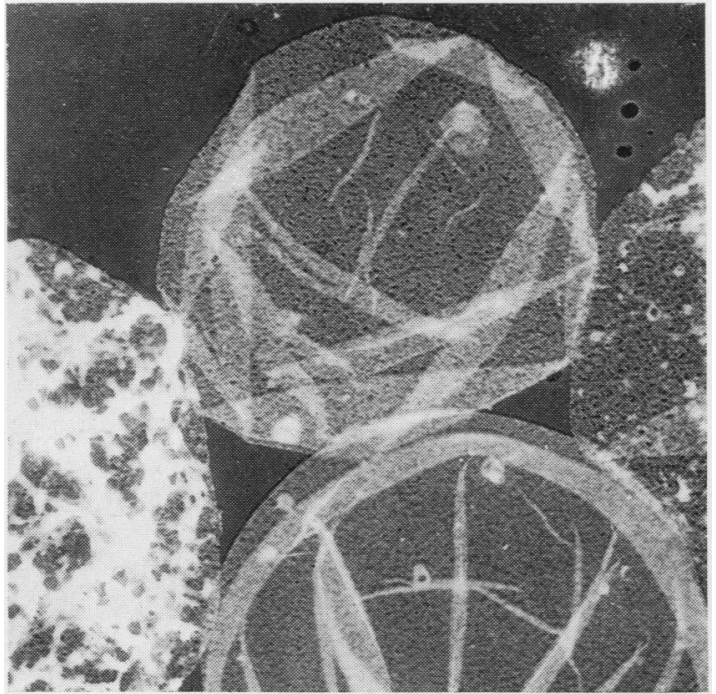

Fig. 1 Red cell membranes from paroxymal nocturnal haemoglobinuria by transmission electron microscopy showing varying amounts of electron-dense material and pitting. $\times 7,000$.

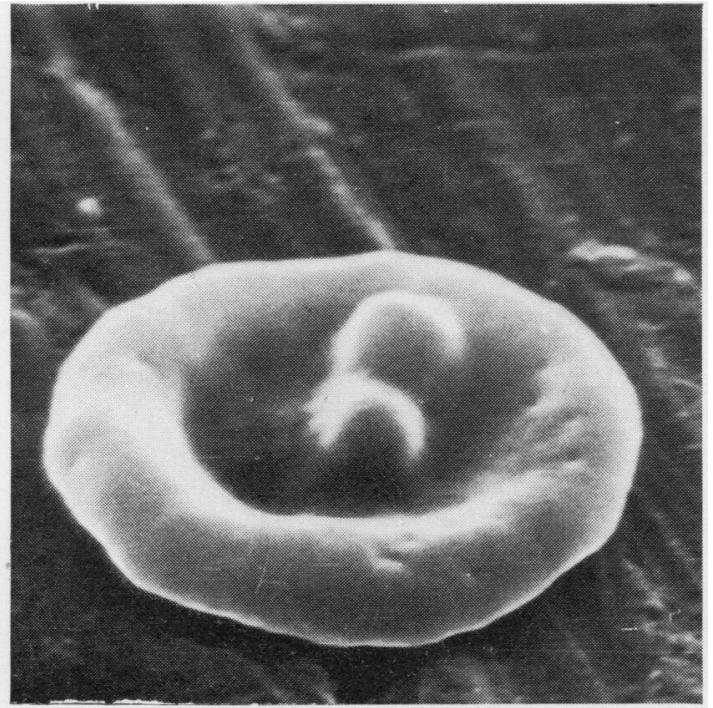

Fig. 3 Red cell from paroxysmal nocturnal haemoglobinuria showing two protuberances at the site of the cell's concavity. Scanning electron microscope. $\times 11,000$.

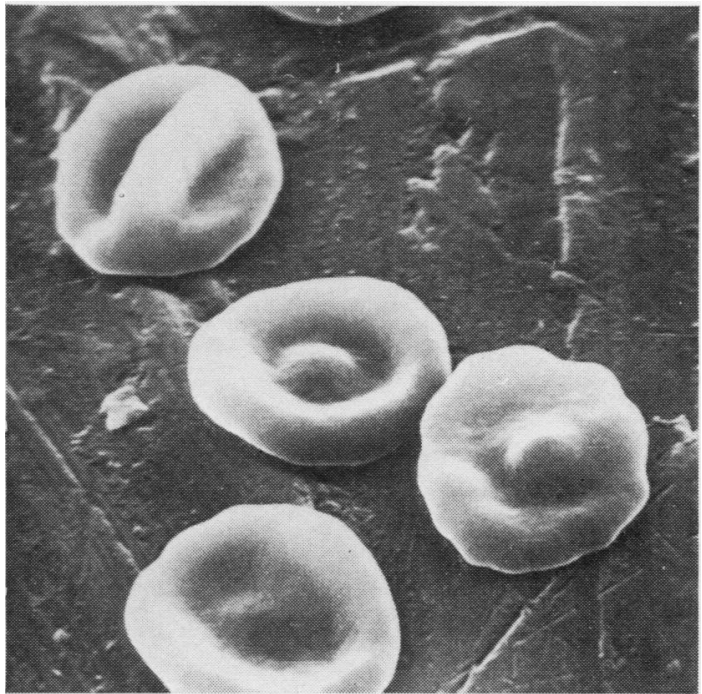

Fig. 2 Red cells from paroxysmal nocturnal haemoglobinuria by scanning electron microscope showing projections and swellings. $\times 5,500$.

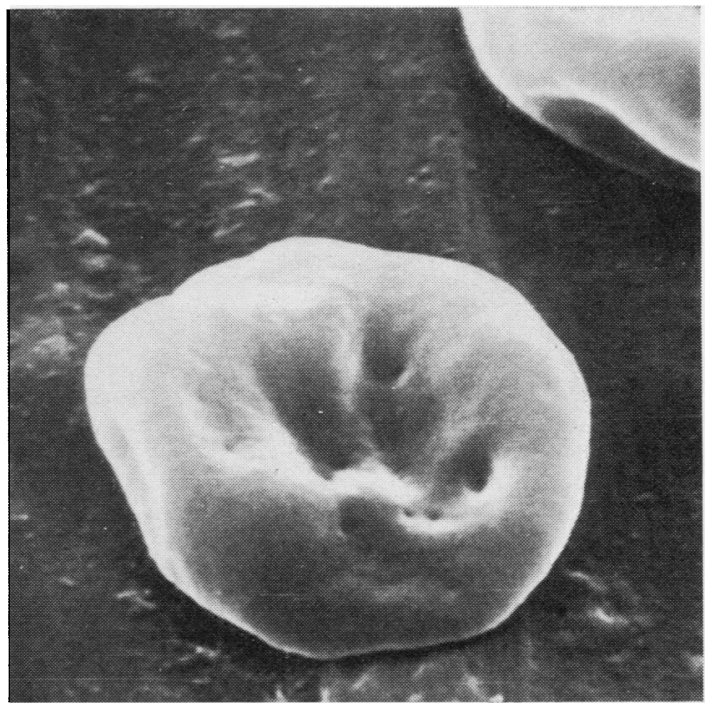

Fig. 4 Red cell from paroxysmal nocturnal haemoglobinuria showing craters. Scanning electron microscope. $\times 11,000$. 


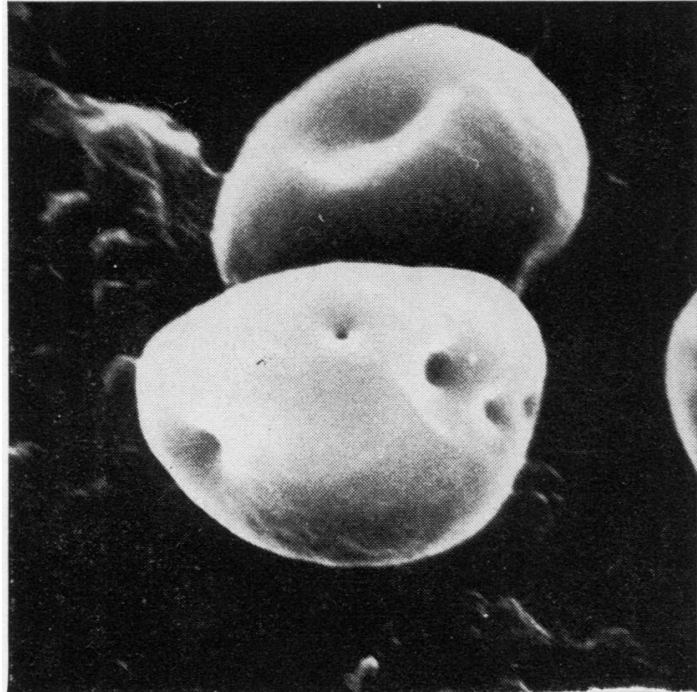

Fig. 5 AET cells, showing sphering, other deformities of shape, and craters. Scanning electron microscope. $\times 11,000$.

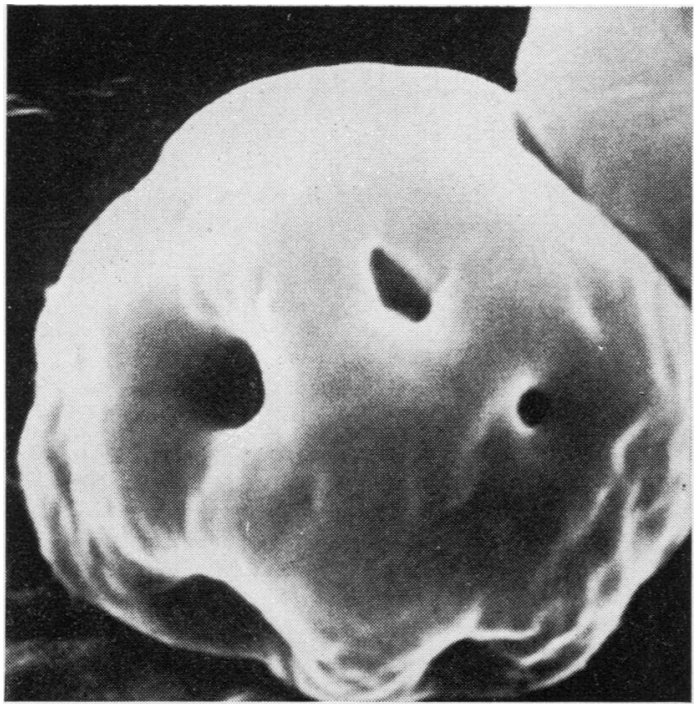

Fig. 7

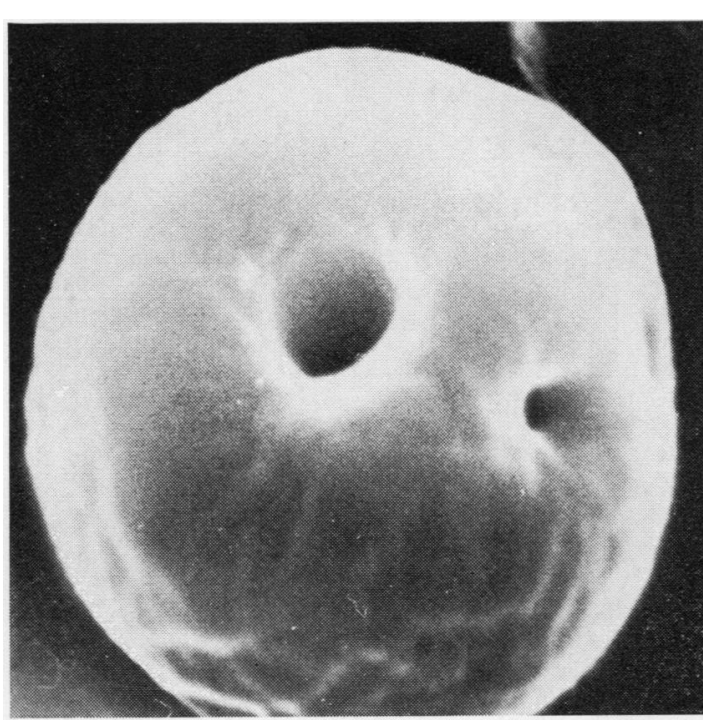

Fig. 6

Figs. 6-8 AET cells with prominent pits and craters. Scanning electron microscope. $\times 14,000$.

Fig. 8

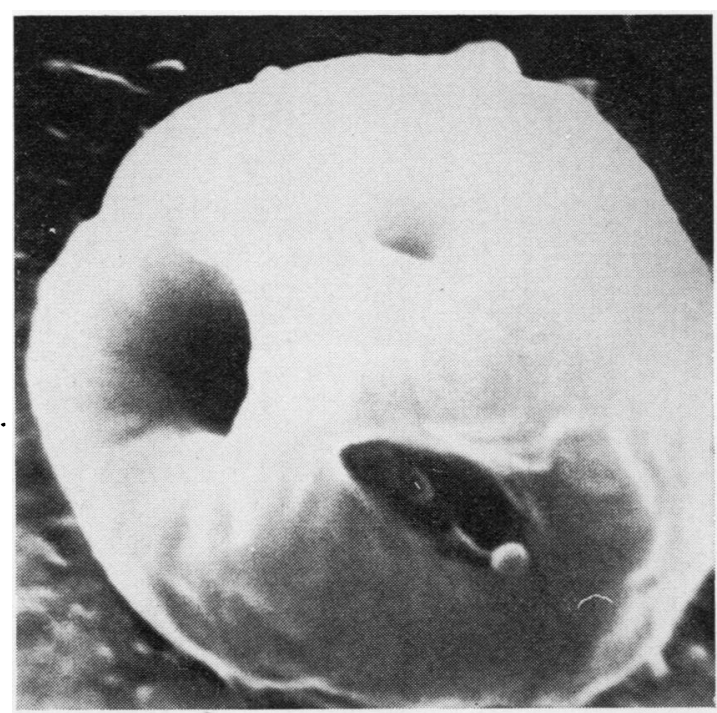

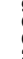




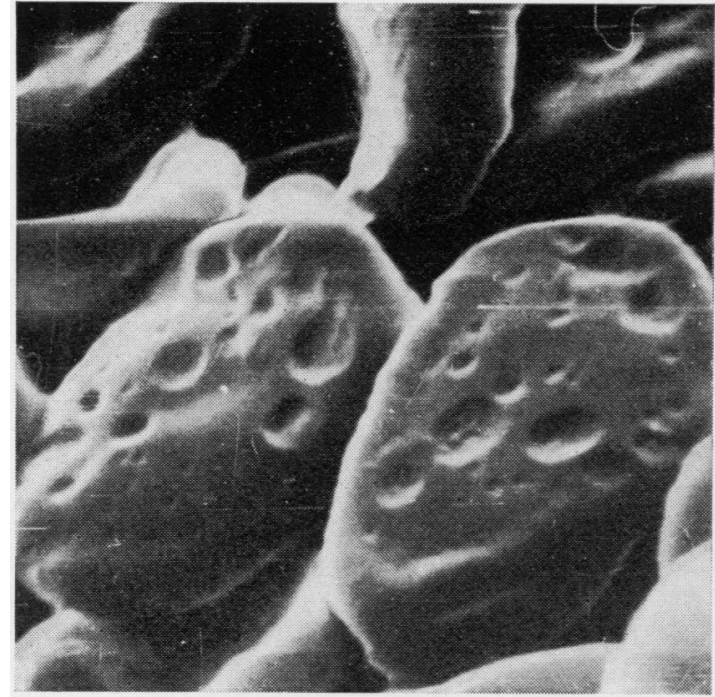

Fig. 9 Paroxysmal nocturnal haemoglobinuria cells after treatment with $2 \% A E T$, showing marked pitting and craters. Scanning electron microscope. $\times 7,000$.

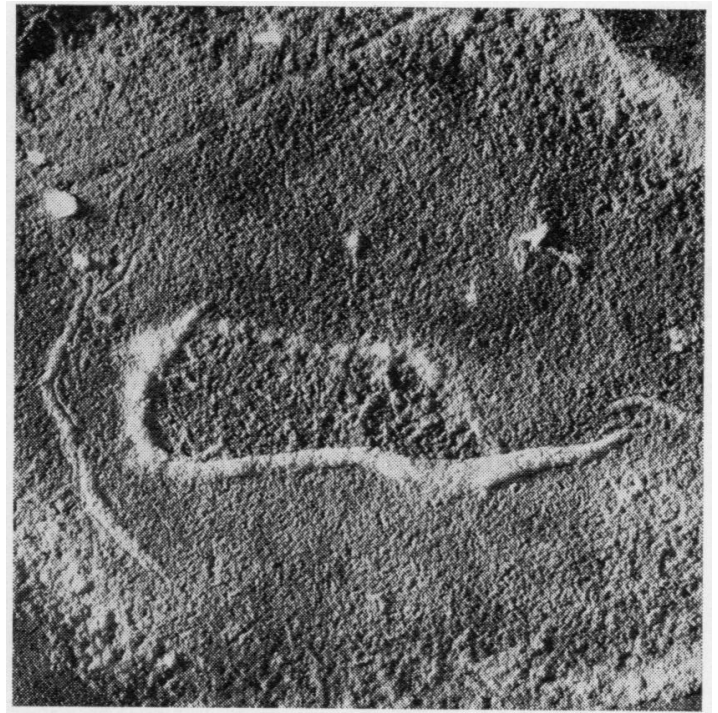

Fig. 10

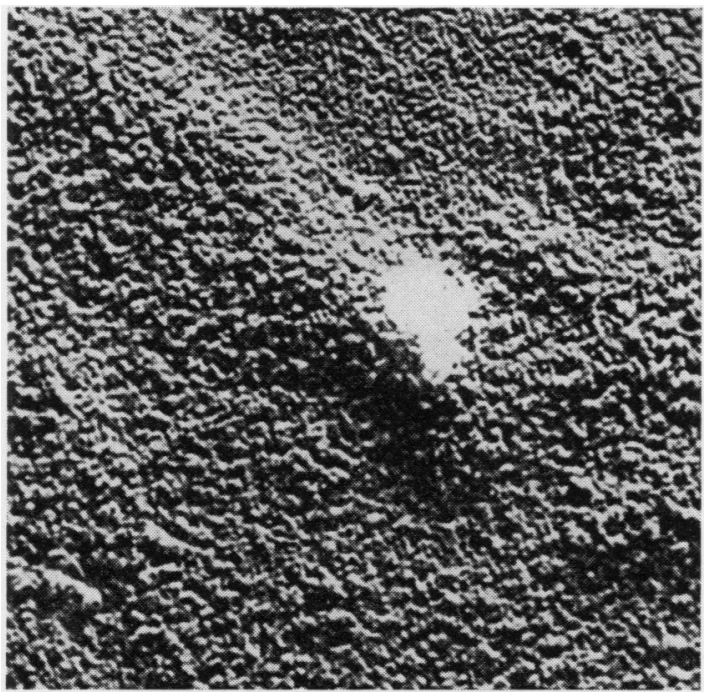

Fig. 11
Figs. 10-11 Membranes from AET cells by transmission electron microscope, showing loss of membrane structure. Figure $10 \times 10,000$, Fig. $11 \times 28,000$. Compare with Figures 12-13. 


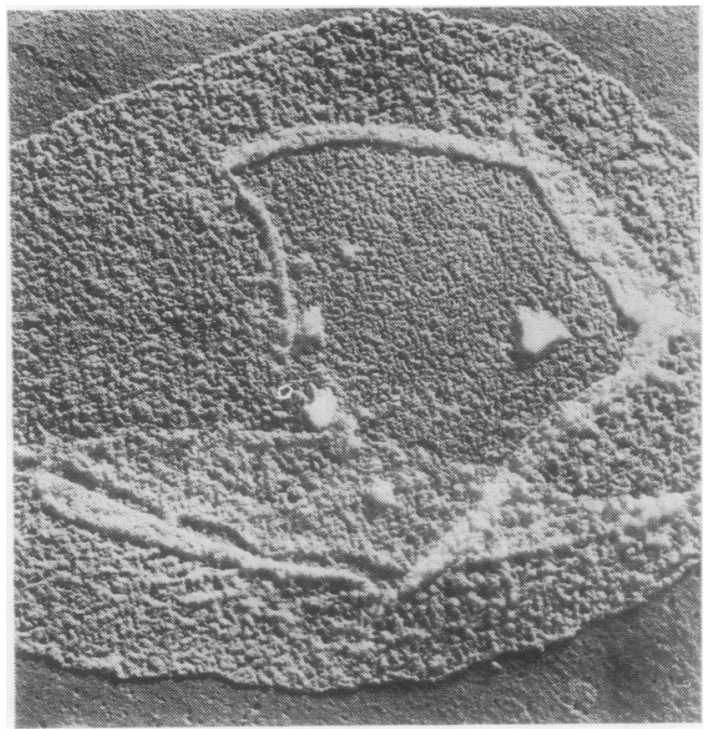

Fig. 12

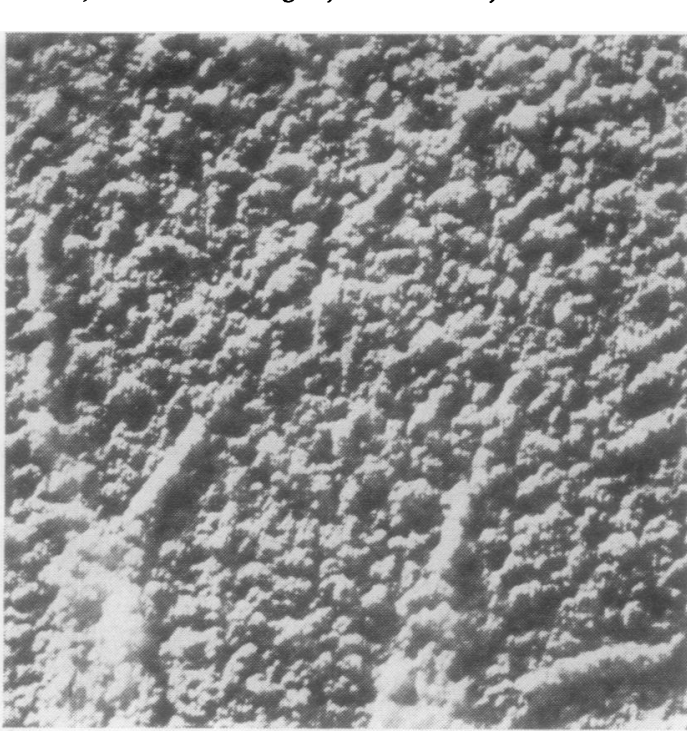

Fig. 13

Figs. 12-13 Normal red cell membranes by transmission electron microscope. Figure $12 \times 10,000$, Fig. $13 \times 28,000$.

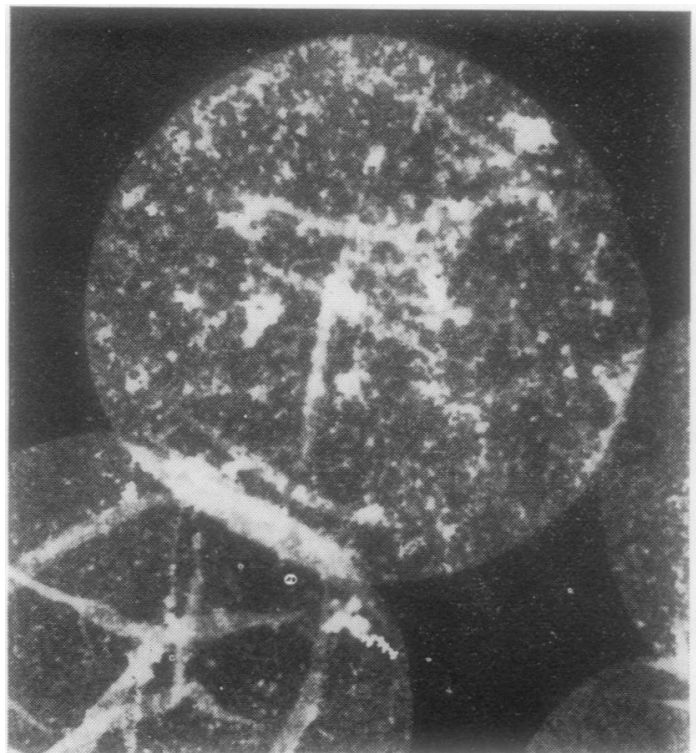

Fig. 14

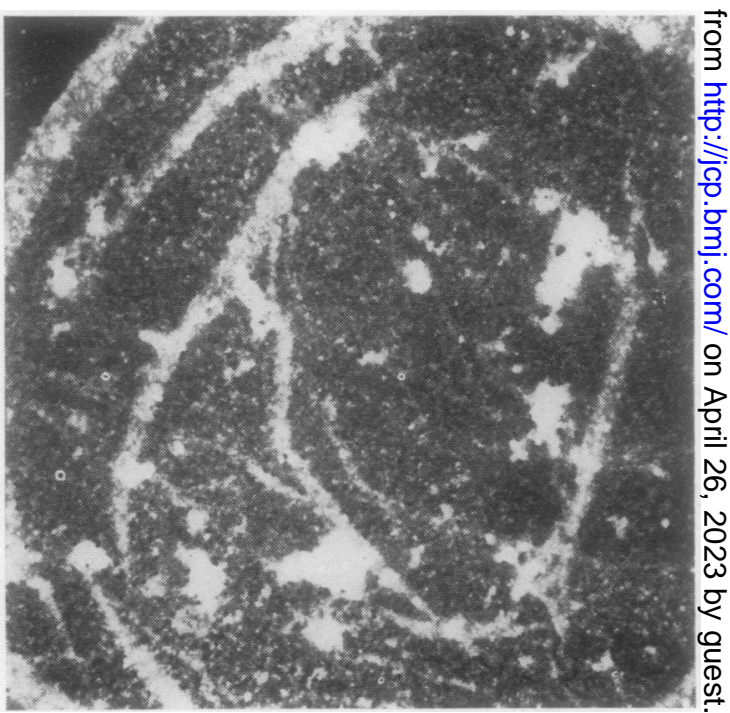

Fig. 15

Figs. 14-15 Membranes of AET cells by transmission electron microscope, showing pitting and electron-dense material. Figure $14 \times 7,000$, Fig. $15 \times 14,000$. 


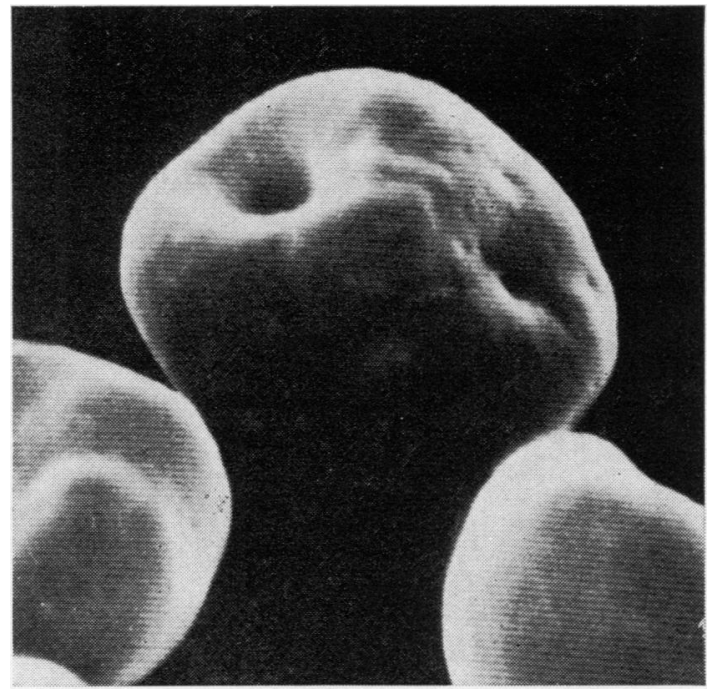

Fig. 16 Red cells after treatment by Nonidet $(1: 10,000)$ for five minutes. Scanning electron microscope. $\times 10,000$.

of preparation, and fixation in glutaraldehyde immediately after collection of the sample should reduce artefacts considerably. There has been only one scanty reference to the examination of blood from a patient with paroxysmal nocturnal haemoglobinuria by the scanning electron microscope (Clarke and Salsbury, 1967). It was thought that the paroxysmal nocturnal haemoglobinuria cells appeared more plastic than normal.

The present study was undertaken partly to try to determine whether the scanning electron microscope would provide any new information on the structure of the red cell membrane and its defect in paroxysmal nocturnal haemoglobinuria, and also to see whether damage from AET resulted in any identifiable ultrastructural alterations in the cell. The findings reported above and illustrated in Figs. 2-4 confirm that there are a number of structural abnormalities in the red cell in paroxysmal nocturnal haemoglobinuria demonstrable by the scanning electron microscope; they include pits and craters which are present in varying numbers in affected cells. These relatively large holes do not appear to be the same pitting defect as is seen by the transmission electron microscope, but as resolution in the scanning instrument used in this study is limited to about $20 \mathrm{~nm}$ it would be difficult to visualize clearly pits of the size of the order seen by the transmission electron microscope. The pitting seen by that instrument appears to be unique to paroxysmal nocturnal haemoglobinuria and has not been observed by us in studies on a wide range of blood disorders (and in normal subjects). On the other hand, the craters and holes seen by the scanning electron microscope are not unique and have been noted, albeit only to a small extent, in red cells from newborn infants and from patients with various anaemias, including congenital and drug-induced haemolytic anaemias (Salsbury and Clarke, 1970; and personal observations).

Another feature of the paroxysmal nocturnal haemoglobinuria cells as seen by the scanning electron microscope was the presence of projections and swellings from the cell surface. It has not been established whether this is a true structural anomaly caused by the defect in the membrane, and occurring either in vivo or in vitro.

The second interest of this present study concerned the effect of AET on red cells in vitro. Cells damaged by AET acquire certain laboratory characteristics of paroxysmal nocturnal haemoglobinuria, notably complement sensitivity with lysis in acidified serum (Sirchia et al, 1965; Sirchia and Dacie, 1967). The electron microscope investigation has demonstrated that these are to some extent paralleled by morphological and ultrastructural changes in the red cells. The changes include variation in shape and size of the cells with sphering; relatively large craters and holes occur on the cell surface (shown by scanning electron microscopy), and in at least some cells there is also evidence of abnormalities in the membrane although these are not identical to those seen in natural cells of paroxysmal nocturnal haemoglobinuria.

The appearances under the scanning electron microscope are not unique to AET cells. They occur naturally in some congenital haemolytic anaemias, drug-induced haemolytic anaemias, and miscellaneous other anaemias (personal observations). Similar appearances may also be seen in cells damaged in vitro by other chemical compounds known to affect the membrane, eg, phenothiazines (Preston and Lee, 1971), and by lipid-dissolving detergent compounds such as Nonidet P40 (BDH Chemicals Ltd) (Fig. 16). These cells do not, however, give a positive acidified serum lysis test.

In paroxysmal nocturnal haemoglobinuria, even in severe cases, the abnormal appearances are much less marked than in AET cells: only a few craters occur in only a proportion of the cells, and there is a much less pronounced alteration of the cell shape. However, when paroxysmal nocturnal haemoglobinuria cells were treated with $2 \%$ AET-an amount which does not damage normal red cellsthe defects became greatly exaggerated (Fig. 9).

We would conclude that the defects in the membrane in AET cells as seen both in scanning and transmission electron microscope preparations bear 
sufficient resemblance to the defects seen in paroxysmal nocturnal haemoglobinuria cells to support the proposition, based on serological and enzymatic studies, that AET cells have many of the characteristics of paroxysmal nocturnal haemoglobinuria cells. The defect induced by AET is, however, not identical with the natural abnormality of paroxysmal nocturnal haemoglobinuria.

This work was supported in part by grants to S.M.L. from the Medical Research Council and Leukaemia Research Fund.

\section{References}

Clarke, J. A., and Salsbury, A. J. (1967). Surface ultramicroscopy of human blood cells. Nature (Lond.), 215, 402-404.

Danon, D., Nevo, A., and Marikovsky, Y. (1956). Preparation of erythrocyte ghosts by gradual haemolysis in hypotonic aqueous solution. Bull. Res. Councl. Israel E., 6, 36-39.

Hayes, T. L., and Pease, R. F. (1968). The scanning electron micro- $\overrightarrow{\bar{F}}$ scope: Principles and applications in biology and medicine.? Advanc. biol. med. Phys., 12, 85-137.

Lewis, S. M., Danon, D., and Marikovsky, Y. (1965). Electronmicroscope studies of the red cell in paroxysmal nocturnal haemoglobinuria. Brit. J. Haemat., 11, 689-695.

Preston, F. E., and Lee, D. (1971). The effects of phenothiazines on $\mathbb{D}$ human erythrocytes: an ultrastructural study. Brit. J. Haemat., 20, 563-566.

Salsbury, A. J., and Clarke, J. A. (1970). A new method for detecting changes in the surface appearance of human red blood cells. J. clin. Path., 20, 603-610.

Sirchia, G., and Dacie, J. V. (1967). Immune lysis of AET-treated $\overrightarrow{-}$ normal red-cells (PNH-like cells). Nature (Lond.), 215, 747-748. W

Sirchia, G., Ferrone, S., and Mercuriali, F. (1965). The action of two sulfhydryl compounds on normal human red cells: relation ship to red cells of paroxysmal nocturnal hemoglobinuria. Blood, 25, 502-510.

Sirchia, G., Ferrone, S., Milani, R., and Mercuriali, F. (1966). Observations on certain enzyme activities of normal human red $\sigma$ cells treated with sulf hydryl compounds. Blood, 28, 98-101. 